\title{
Uptake of ${ }^{14} \mathrm{C}$-streptomycin by some Micro-organisms and its Relation to their Streptomycin Sensitivity
}

\author{
By R. HANCOCK* \\ Department of Bacteriology, University of Manchester
}

(Received 14 September 1961)

\begin{abstract}
SUMMARY
The uptake of radioactivity from ${ }^{14} \mathrm{C}$-streptomycin, in a form which cannot be displaced from theorganisms by unlabelled streptomycin, was determined in several species of bacteria and one yeast growing under standard conditions. This uptake showed a good correlation with the sensitivity of the organism to streptomycin, and in streptomycin-resistant organisms was about $1 \%$ of that in a highly sensitive organism, Bacillus megaterium. The quantity of streptomycin taken up when growth ceased represented an intracellular concentration 10- to 50-fold higher than that in the growth medium. Environmental factors, such as anaerobiosis or presence of carbon monoxide, which increased the resistance of Staphylococcus aureus to streptomycin also resulted in decreased rates of uptake of ${ }^{14} \mathrm{C}$-streptomycin. When Bacillus subtilis grew in medium containing the streptomycin antagonist 2 - $n$-heptyl-4-hydroxyquinoline $N$-oxide, the rate of uptake of radioactivity was reduced to about $30 \%$ of that in absence of the antagonist; the rate at which harvested organisms oxidized succinate and malate was reduced to a similar extent.
\end{abstract}

\section{INTRODUCTION}

The uptake of streptomycin by bacterial cells has been investigated on a number of occasions with organisms under different experimental conditions and by various methods for estimating the amount of streptomycin taken up. In early work, Linz (1949) estimated biologically the antibiotic activity released on lysing streptomycintreated Micrococcus lysodeikticus with lysozyme; Linz \& Arnaud (1950) studied some other organisms using extraction with warm salt solutions, and Berkman, Henry, Housewright \& Henry (1948) studied uptake by dense suspensions of Staphylococcus aureus. These investigations showed that, under the conditions used, only about 1-3 \% of the total streptomycin present was taken up, and that cells of streptomycin-resistant and sensitive strains took up similar amounts of streptomycin. Since it is now known that streptomycin is not bactericidal to Escherichia coli or Staphylococcus aureus when the organisms are prevented from growing (Anand \& Davis, 1960; Hancock, 1960), the results of these earlier studies using non-growing organisms may not be relevant to the processes leading to death of the organisms.

More detailed studies of streptomycin uptake have been made possible recently by the use of ${ }^{14} \mathrm{C}$-labelled streptomycin. Szybalski \& Mashima (1959) showed that Escherichia coli $\mathrm{K} 12$ took up radioactivity during the period during which viability was lost following addition of ${ }^{14} \mathrm{C}$-streptomycin, whereas streptomycin-resistant

* Present address: Department of Bacteriology and Immunology, Harvard Medical School, Boston 15, U.S.A. 
organisms took up a negligible amount; in these experiments, only that streptomycin which was not removed by washing with solutions containing unlabelled streptomycin was determined. The kinetics of uptake of streptomycin by $\boldsymbol{E}$. coli $\mathbf{W}$ were studied by Anand, Davis \& Armitage (1960) and by Plotz, Dubin \& Davis (1961); an initial rapid uptake, similar in both sensitive and resistant organisms, was followed by a second slower uptake which occurred only in sensitive organisms and depended on growth of the organisms. A rapid uptake of streptomycin, by a process similar to adsorption and resulting in a change in the charge of the cell surface, had been observed earlier in E. coli $\mathbf{H}$ and in Staphylococcus aureus (McQuillen, 1951).

The experiments described in the present paper had the particular object of investigating the relationship between sensitivity to, and uptake of, streptomycin, in organisms of different sensitivity and in environments which affect the activity of streptomycin on particular organisms. Some of these results have been published in abstract (Hancock, $1961 a$ ).

\section{METHODS}

Organisms and media. The following organisms were used: Bacillus subtilis, originally National Collection of Type Cultures (NCTC) no. 8236 but now of different streptomycin-sensitivity; B. megaterium KM; B. pumilis NCTC 8241; Escherichia coli B; Streptococcus faecalis NCTC 8213; Clostridum welchii SR 12; Cl. sporogenes NCTC 532; Staphylococcus aureus Duncan and a streptomycin-resistant strain derived from it; $S$. aureus strains 57 and 60, clinical isolates obtained from Dr R. M. Stirland of this Department; Candida utilis IMI 23311 (Commonwealth Mycological Institute, Kew).

Candida utilis and Bacillus megaterium were grown in C medium (McQuillen \& Roberts, 1954) + glucose (1 mg. $/ \mathrm{ml}$.) + Difco Yeast extract $(0 \cdot 1 \mathrm{mg} . / \mathrm{ml}$.) (named here CGY medium). The other organisms were grown in nutrient broth (Difco No. 2; $\mathrm{pH} 7 \cdot 5)$, with addition of glucose $(1 \mathrm{mg} . / \mathrm{ml}$.) for the staphylococci. Cultures were grown in $100 \mathrm{ml}$. quantities of medium in $250 \mathrm{ml}$. Erlenmeyer flasks fitted with side arms to fit the Unicam SP 600 spectrophotometer. The prewarmed medium was inoculated from an overnight culture to give an initial population density equivalent to about $50 \mu \mathrm{g}$. dry wt. organism $/ \mathrm{ml}$., estimated from the optical density $(700 \mathrm{~m} \mu)$ and a calibration curve for the appropriate organism. Flasks containing cultures of clostridia were evacuated and gassed with $\mathrm{N}_{2}$ and incubated statically at $37^{\circ}$; cultures of other organisms were shaken in a constant temperature water bath at $37^{\circ}$. For growth of Staphylococcus aureus in a gas phase containing carbon monoxide, the flasks were successively evacuated and filled three times with the appropriate gas mixture, which was prepared in an aspirator from cylinder carbon monoxide and air. Organisms were harvested by centrifugation $(6000 \mathrm{~g} ; 5 \mathrm{~min}$.) and, unless otherwise stated, washed once with cold growth medium. When ${ }^{14} \mathrm{C}$-streptomycin was used, the washing medium contained unlabelled streptomycin (100 $\mu \mathrm{g} . / \mathrm{ml}$.).

Sensitivity tests. The minimum inhibitory concentrations of streptomycin for the organisms used were determined by a conventional technique. Tubes containing $2.5 \mathrm{ml}$. of appropriate medium, with streptomycin added when required, were inoculated with 1 drop of a similar culture grown for $24 \mathrm{hr}$., and were incubated for 24. hr. at $37^{\circ}$.

Radioactivity determinations. The relatively low specific activity of the ${ }^{14} \mathrm{C}$-strepto- 
mycin preparation necessitated the use of a windowless gas-flow Geiger counter, made in the workshops of this department and based on the design of Banks, Blow \& Francis (1956); the flushing gas was $1.5 \%(v / v)$ isobutane in argon. Since the observed radioactivities were low by usual standards, it was important to know their limits of accuracy. It was repeatedly found that the standard deviation of ten estimates of background and of experimental samples, counted for 2 min. periods, was not more than that expected statistically. At least 400 counts were recorded from all samples, which were prepared and counted in duplicate, so that the standard deviation of the mean value of the difference (sample-background) was not more than 40 counts, or $5 \%$. Unless specifically stated, all the results in this and the following paper are from samples which contained between 20 and 200 counts/min. above background, which varied over long periods between 23 and 27 counts/min.

Samples were mounted on aluminium planchets of $2 \mathrm{~cm}$. diameter, as described elsewhere (Park \& Hancock, 1960); these were weighed before and after mounting and drying the samples, which usually contained less than $20 \mathrm{mg}$. dry wt. of material. The observed radioactivity was corrected to infinite thinness, when necessary, by using a self-absorption curve determined experimentally by preparing planchets containing different quantities of Bacillus megaterium and a standard amount of ${ }^{14} \mathrm{C}$-streptomycin. It was assumed that this curve was applicable to all the organisms used.

Manometric experiments with Bacillus subtilis were carried out under conditions described previously (Hancock, $1961 b$ ); the manometer flasks contained the equiv. of about $4 \mathrm{mg}$. dry wt. organisms.

Streptomycin. ${ }^{14} \mathrm{C}$-streptomycin $\mathrm{CaCl}_{2}$ complex was preparation $\mathrm{L}$ 561034-1-4 of Merck, Sharpe and Dohme Research Laboratories. The specific activity was such that 47 counts/min. were recorded from $1 \mu \mathrm{g}$. streptomycin base. Concentrations of streptomycin are given throughout in terms of the free base. $2-n$-heptyl-4-hydroxyquinoline $N$-oxide was kept as a solution containing $50 \mu \mathrm{g} . / \mathrm{ml}$. in $0.01 \mathrm{~N}-\mathrm{NaOH}$.

\section{RESULTS}

Effects of washing. It was not practicable to carry out detailed investigations of the effects of washing on each organism. However, some radioactivity was removed from all those organisms investigated, with the exception of Bacillus megaterium, by washing in growth medium containing unlabelled streptomycin (Table 1). The radioactivity removed in this way may represent streptomycin bound in a manner similar to that bound in the initial phase of streptomycin action in Escherichia coli $\mathrm{W}$, which can be removed by washing with buffers but not with distilled water (Anand $e$ t al. 1960). In addition, in the organisms studied here some streptomycin may be bound to negatively charged cell-wall constituents, such as teichoic or teichuronic acids. It was also not practicable to show that the radioactivity taken up by each organism represented unaltered streptomycin; it is expressed in terms of streptomycin in this paper, but its identity has only been shown in the case of B. megaterium (Hancock 1962).

\section{Rate of uptake of streptomycin by growing organisms}

To compare the rates of uptake of streptomycin by different organisms, standard experimental conditions were used in which streptomycin was added to $10 \mu \mathrm{g} . / \mathrm{ml}$ 
to an exponentially growing culture when the population density was about equiv. to $100 \mu \mathrm{g}$. dry wt. organisms $/ \mathrm{ml}$. There was a good correlation between the rate of uptake of streptomycin under these conditions and the sensitivity to streptomycin, within the group of organisms investigated (Fig. 1). Both naturally resistant organisms (e.g. the clostridia), and resistant strains of normally sensitive organisms, showed rates of uptake of the order of $1 \%$ of that in the most sensitive organism used, Bacillus megaterium. The quantity of streptomycin finally taken up by some of these organisms was also determined, when using streptomycin at concentrations which inhibit growth completely after about $1 \mathrm{hr}$. (Table 2).

\section{Table 1. Retention of ${ }^{14} \mathrm{C}$-streptomycin on washing}

Several identical samples of each culture were harvested when inibition of growth was just complete, except in the experiments in the first and last columns. With the exception of Bacillus megaterium which was harvested and washed on membrane filters, the organisms were harvested by centrifugation.

Control (unwashed)

Washed $\times 3$ with growth medium

Washed with growth medium containing unlabelled streptomycin $(100 \mu \mathrm{g} . / \mathrm{ml}) \quad.\{\times 3$

Washed $\times 2$ with $\mathrm{M}-\mathrm{NaCl}$
Organism

\begin{tabular}{|c|c|c|c|c|}
\hline & $u m$ & $\begin{array}{c}\text { Staphylococcus } \\
\text { aureus }\end{array}$ & $\begin{array}{c}\text { Bacillus } \\
\text { subtilis }\end{array}$ & $\begin{array}{c}\text { Clostridium } \\
\text { welchii }\end{array}$ \\
\hline \multicolumn{5}{|c|}{ Concentration of streptomycin $(\mu \mathrm{g} . / \mathrm{ml})}$. \\
\hline 1 & 1 & 12 & 40 & 10 \\
\hline \multicolumn{5}{|c|}{ Time of exposure (min.) } \\
\hline 30 & 60 & 120 & 120 & 120 \\
\hline \multicolumn{5}{|c|}{ Counts/min./sample } \\
\hline 39 & 74 & 479 & 213 & 79 \\
\hline 40 & 73 & - & - & - \\
\hline 38 & 70 & 210 & 138 & 28 \\
\hline 39 & 65 & 201 & 143 & 27 \\
\hline 34 & 68 & - & - & - \\
\hline
\end{tabular}

Table 2. Quantity of streptomycin taken up when growth is fully inhibited

Organisms were harvested when growth had just ceased, and washed once in growth medium containing unlabelled streptomycin $(100 \mu \mathrm{g} . / \mathrm{ml}$.). The results are from three separate experiments for Bacillus megaterium.

$\begin{array}{cccc}\text { Bacillus } & \text { Staphylococcus } & \text { Bacillus } & \text { Escherichia } \\ \text { megaterium } & \text { aureus } & \text { subtilis } & \text { coli }\end{array}$

Concentration of streptomycin ( $\mu \mathrm{g} . / \mathrm{ml}$.)

$$
1 \quad 10
$$

Time of exposure (min.)

$$
125
$$

Final number of viable organisms, \% initial value

$$
\mathbf{0 . 2}
$$

40

120

0.7
10

70

Final uptake of streptomycin ( $\mu \mathrm{g} \cdot / \mathrm{g}$. dry wt.) 


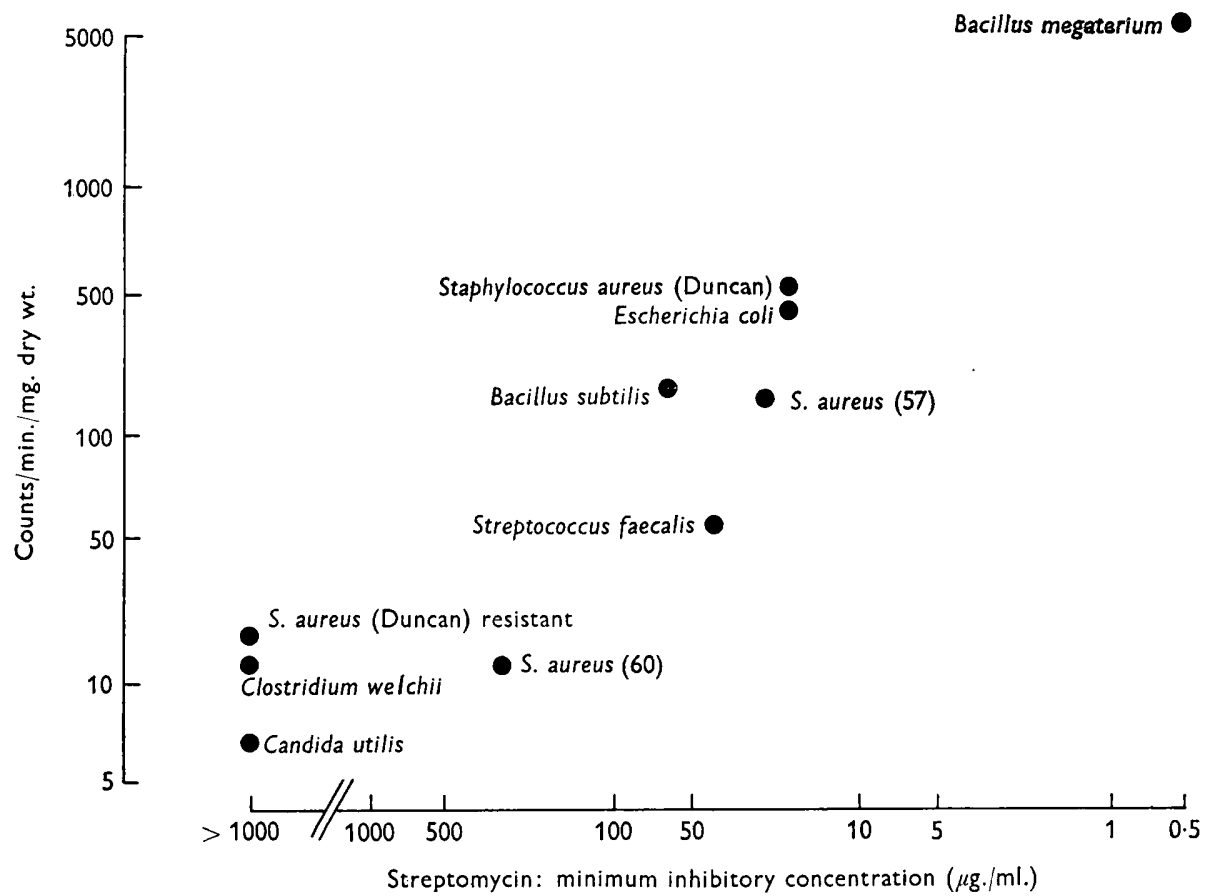

Fig. 1. Minimum inhibitory concentrations of streptomycin for some micro-organisms and uptake of ${ }^{14} \mathrm{C}$-streptomycin during growth under standard conditions. Uptake was determined with streptomycin at $10 \mu \mathrm{g}$. $/ \mathrm{ml}$. after growth for $60 \mathrm{~min}$., except for Bacillus megaterium where the rate is calculated from that for the first $15 \mathrm{~min}$. period, after which loss of viability began.

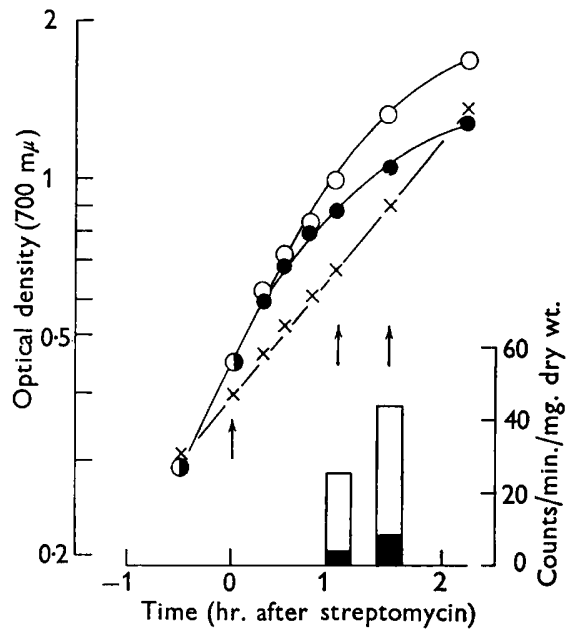

A

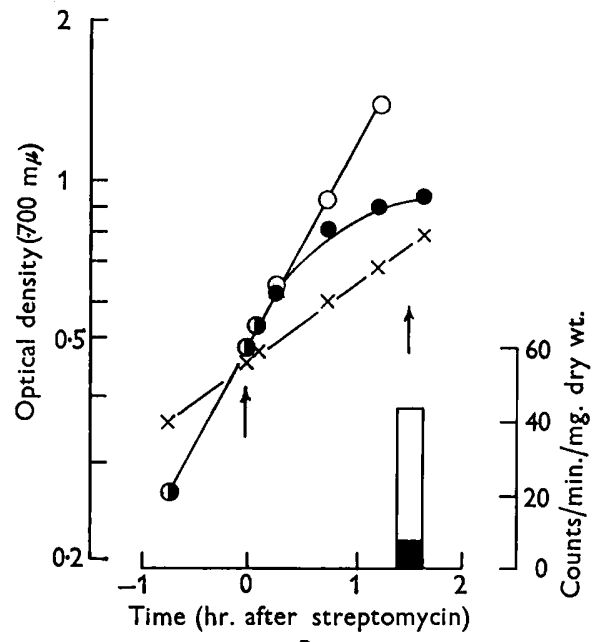

B

Fig. 2. Uptake of ${ }^{14} \mathrm{C}$-streptomycin by Staphylococcus aureus following addition of streptomycin $(8 \mu \mathrm{g} . / \mathrm{ml}$.) at first arrow. Points represent optical density of cultures without streptomycin $(O)$; with streptomycin in $\operatorname{air}(O)$; and with or without streptomycin $(x)$ in nitrogen (A) or in $80 \%(\mathrm{v} / \mathrm{v})$ carbon monoxide in air (B). Columns represent radioactivity of organisms, at times indicated by arrows, in air (open columns) or in other gases (solid columns). 
Uptake of streptomycin by Staphylococcus aureus during anaerobic growth

Facultatively anaerobic organisms such as Staphylococcus aureus are more resistant to streptomycin during anaerobic growth, and also during growth in the presence of carbon monoxide (Lightbown, 1957). When $S$. aureus was grown anaerobically the uptake of streptomycin was about $20 \%$ of that during aerobic growth (Fig. 2A), although the anaerobic growth rate was about $65 \%$ of the aerobic rate. Similar results were obtained with cultures growing in a gas mixture of $80 \%(\mathrm{v} / \mathrm{v})$ carbon monoxide $+20 \%(\mathrm{v} / \mathrm{v})$ air (Fig. 2B).

\section{Effect of streptomycin antagonists on uptake of streptomycin by Bacillus subtilis}

The inhibitory action of streptomycin on Bacillus subtilis and some other organisms can be antagonized by certain alkyl-hydroxyquinoline $N$-oxides (Lightbown, 1954) at concentration ratios of antagonist:streptomycin of the order

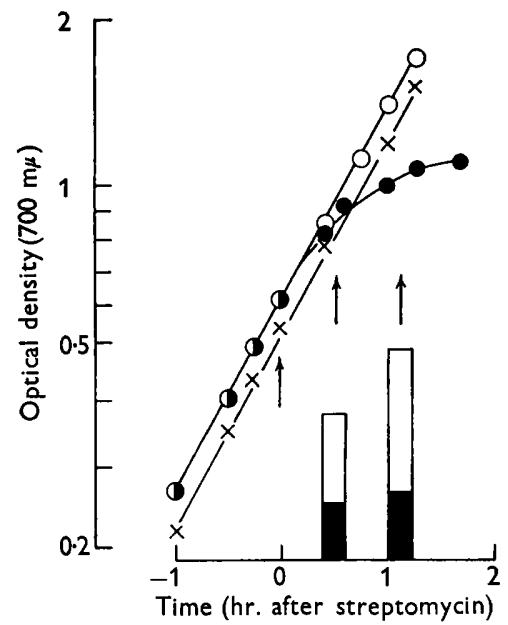

Fig. 3

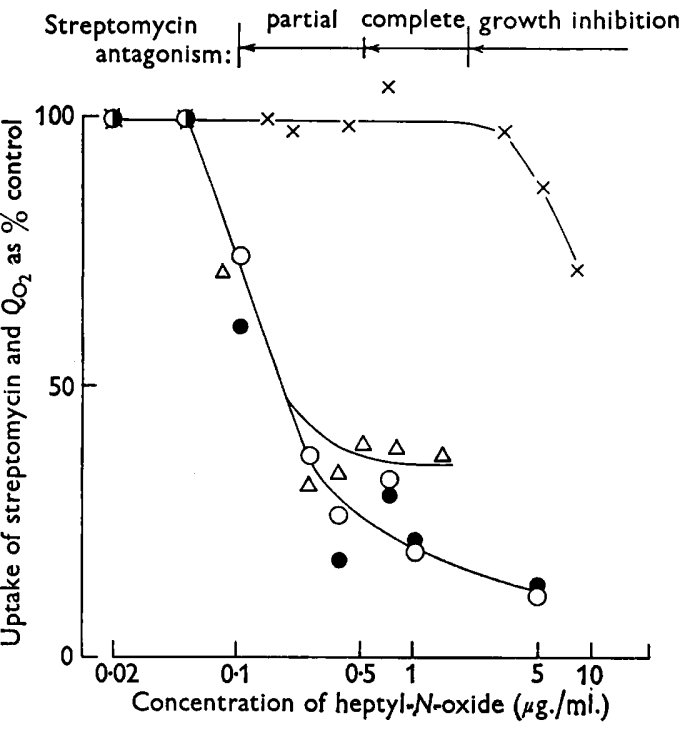

Fig. 4

Fig. 3. Effect of heptyl-N-oxide on growth of Bacillus subtilis and uptake of ${ }^{14} \mathrm{C}$-streptomycin $(30 \mu \mathrm{g} . / \mathrm{ml}$.) added at the first arrow. Points represent optical density of cultures without streptomycin (O), with streptomycin alone (๑), and with both streptomycin and heptyl- $N$-oxide $(0.35 \mu \mathrm{g} . / \mathrm{ml}$.) $(\times)$. Columns represent radioactivity of organisms, at times indicated by arrows, with streptomycin alone (open columns) or with both streptomycin and heptyl- $N$-oxide (solid columns).

Fig. 4. Uptake of ${ }^{14} \mathrm{C}$-streptomycin by Bacillus subtilis in cultures containing heptyl- $N$ oxide $(\triangle)$, and ability of organisms to oxidize glucose $(x)$, succinate $(\bullet)$ and malate $(O)$, relative to values in control cultures without heptyl- $N$-oxide. ${ }^{14} \mathrm{C}$-streptomycin was added at subinhibitory concentration $(18 \mu \mathrm{g} . / \mathrm{ml}$.) to cultures when the optical density ( $700 \mathrm{~m} \mu)$ was 0.3 ; the organisms were harvested after $90 \mathrm{~min}$., when control organisms contained between 31 and 44 , counts/min./mg. dry weight. $Q_{O_{2}}$ values were determined using organisms harvested after growth for $60 \mathrm{~min}$. with heptyl- $N$-oxide, which was added to cultures when the optical density was $0 \cdot 15$. Antagonism of streptomycin, or inhibition of growth, by heptyl- $N$-oxide was determined from the optical density of growing cultures when heptyl- $N$-oxide was added at an optical density of 0.15 and streptomycin (50 $\mu \mathrm{g} . / \mathrm{ml}$.) at an optical density of $0 \cdot 3$. The growth rate was not affected by heptyl- $N$ oxide at concentrations below $2 \mu \mathrm{g}$. $/ \mathrm{ml}$., but at concentrations greater than this the growth rate was reduced. 
of 1:100. At low concentrations, 2- $n$-heptyl-4-hydroxyquinoline $N$-oxide (heptyl$N$-oxide) did not affect the growth rate of $B$. subtilis but conferred complete resistance to subsequent addition of streptomycin. The uptake of streptomycin in such cultures was between 30 and $40 \%$ of the rate in a control culture without heptyl- $N$-oxide (Fig. 3).

Since heptyl- $N$-oxide is known to be an inhibitor of certain respiratory systems in resting bacteria and cell-free preparations (Lightbown \& Jackson, 1956), we examined whether the respiratory activities of organisms growing in its presence were similarly affected. When organisms were harvested from cultures containing heptyl- $N$-oxide at concentrations which antagonize streptomycin but did not affect the growth rate, their ability to oxidize succinate and malate was below the control values although oxidation of glucose was not affected (Fig. 4). At higher concentrations, heptyl- $N$-oxide has itself growth-inhibitory activity, and in cultures containing the antagonist at these concentrations the ability of harvested organisms to oxidize glucose was also impaired. The rate of uptake of streptomycin, determined in similar cultures, was depressed during growth in the presence of heptyl- $N$-oxide to an extent very similar to that of oxidation of succinate and malate (Fig. 4).

\section{DISCUSSION}

Many types of process can be envisaged by which micro-organisms can become resistant to an antibacterial agent (Davis \& Maas, 1952); among these are alterations in the metabolic pathways used by the organisms, an alteration in the rate of uptake of the agent into the organism or to its site of action, or an enzymic inactivation of the antibiotic. In all the cases investigated here, and within the limits of the assumptions made about the use of the same washing procedure for each organism (which may have to be modified in the light of further experience), resistance to streptomycin, determined either genetically or by environmental factors, was associated with a decreased uptake of streptomycin. This relationship is similar to that in Escherichia coli K 12 (Szybalski \& Mashima, 1959) and in the secondary phase of uptake in $E$. coli W (Anand et al. 1960); however, in the latter organism the initial uptake of streptomycin is the same in sensitive and resistant organisms. It differs from earlier findings of Linz (1949) and of Berkman et al. (1948), and from those of Sager (1961) in Chlamydomonas reinhardi. A similar relationship is found between sensitivity to, and rate of uptake of, penicillin in naturally occurring strains, though not in laboratory strains, of staphylococci (Rowley, Cooper, Roberts \& Lester Smith, 1950; Eagle, 1954). Such a correlation between sensitivity and rate of uptake of streptomycin makes it unnecessary to postulate differences in, or absence of, the streptomycin-sensitive metabolic processes in streptomycinresistant organisms. However, such differences cannot be excluded because if uptake of streptomycin were caused directly by its interference in a metabolic system, for example, by combination with an enzyme, metabolite, or structural unit, then organisms which lacked this system would be resistant to streptomycin and also would not take up streptomycin.

The quantity of streptomycin taken up when growth has ceased differed considerably in each organism examined here, but in every case it represented a concentration of streptomycin within the cell higher than that outside if the streptomycin is distributed throughout the water space of the organisms. Thus, using the 
values of Mitchell \& Moyle (1956) for the water spaces of Escherichia coli and Staphylococcus aureus, and of Weibull (1955) for Bacillus megaterium, the intracellular concentrations finally attained, calculated from the results in Table 2, are 110,480 , and $11 \mu \mathrm{g} . / \mathrm{ml}$., at external concentrations of 10,10 , and $1 \mu \mathrm{g} . / \mathrm{ml}$., respectively.

Sensitivity of bacteria to streptomycin shows some general correlation with the degree of dependence on, or use of, aerobic respiratory processes, and the rate of uptake of the antibiotic also shows some correlation with those factors. The suppression of ability to oxidize succinate and malate by organisms growing in the presence of the streptomycin antagonist heptyl $N$-oxide shows that the inhibition of these reactions in resting organisms (suggested as the basis for antagonism of streptomycin, Lightbown \& Jackson, 1956), also occurs in growing organisms precisely at those concentrations which confer resistance to streptomycin. It may perhaps be reemphasized that these alterations occur without any effect on the growth rate of the organisms. It remains to be investigated whether the suppression of these oxidative activities is due to a reduction in enzyme formation or merely in activity. It is interesting to speculate that the residual oxidation of succinate and malate in the presence of heptyl $N$-oxide, and also the reactions involved in glucose oxidation, may be mediated through the flavoprotein oxidative systems which occur in Bacillus subtilis (Lightbown \& Kogut, 1959). The close correlation in B. subtilis between the ability to oxidize succinate and malate and the rate of uptake of streptomycin suggests that streptomycin uptake may be closely related to the rate of operation of either the electron transport systems for these substrates or of the terminal oxidation pathways, such as the tricarboxylic acid cycle, which depend on them.

I am grateful to Dr J. W. Lightbown for a gift of 2-n-heptyl-4-hydroxyquinoline $N$-oxide.

\section{REFERENCES}

Anand, N. \& Davis, B. D. (1960). Damage by streptomycin to the cell membrane of Escherichia coli. Nature, Lond. 185, 22.

Anand, N., Davis, B. D. \& Armitage, A. K. (1960). Uptake of streptomycin by Escherichia coli. Nature, Lond. 185, 23.

Banks, T. E., Blow, L. W. \& Francis, G. E. (1956). A windowless flow-type Geiger counter for the assay of solid materials containing soft $\beta$-emitting isotopes. Biochem. $J$. 64, 408.

Berkman, S., Henry, R. J., Housewright, R. D. \& Henry, J. (1948). Streptomycin. IV. Adsorption of streptomycin by susceptible and resistant bacteria. Proc. Soc. exp. biol. Med., N.Y. 48, 65 .

Davis, B. D. \& MaAs, W. K. (1952). Analysis of the biochemical mechanism of drug resistance in certain bacterial mutants. Proc. nat. Acad. Sci., Wash. 38, 775.

EAGLE, H. J. (1954). The binding of penicillin in relation to its cytotoxic action. J. exp. Med. $100,103$.

HANCOCK, R. (1960). The bactericidal action of streptomycin on Staphylococcus aureus and some accompanying biochemical changes. J. gen. Microbiol. 23, 179.

HaNCOCK, R. (1961 $a$ ). Reduced uptake of ${ }^{14} \mathrm{C}$-streptomycin by bacteria in the presence of respiratory inhibitors and under anaerobic conditions. Biochem. J. 78, $7 \mathrm{P}$.

HANCOCK, R. (1961 b). Reduced oxidative activities in Escherichia coli and Bacillus megaterium in relation to other changes during inhibition of growth by streptomycin. J. gen. Microbiol. 25, 429. 
HANCOCK, R. (1962). Uptake of ${ }^{14} \mathrm{C}$-streptomycin by Bacillus megaterium. J. gen. Microbiol.

Lrghtвown, J. W. (1954). An antagonist of streptomycin and dihydrostreptomycin produced by Pseudomonas aeruginosa. J. gen. Microbiol. 11, 477.

Lightbown, J. W. (1957). Metabolic processes underlying streptomycin resistance. G. ital. Chemioter. 4, 22.

Lightbown, J. W. \& JACKson, F. L. (1956). Inhibition of cytochrome systems of heart muscle and certain bacteria by the antagonists of dihydrostreptomycin: 2-alkyl-4-hydroxyquinoline $N$-oxides. Biochem. $J .63,130$.

Lightвown, J. W. \& Kogut, M. (1959). Soluble enzymes catalysing the oxidation of reduced diphosphopyridinenucleotide by molecular oxygen and hydrogen peroxide isolated from Bacillus subtilis. Biochem. J. 73, 14. P.

Linz, R. (1949). Sur le mécanisme de l'action de la streptomycine. Ann. Inst. Pasteur, 76, 250.

Linz, R. \& ARnaud, Y. (1950). Influence de quelques facteurs sur la fixation de la streptomycine par Mycobacterium tuberculosis. C.R. Soc. Biol., Paris, 144, 1554.

McQuillen, K. (1951). The bacterial surface. 4. Effect of streptomycin on the electrophoretic mobility of Escherichia coli and Staphylococcus aureus. Biochim. Biophys. Acta, 7,54 .

McQuillen, K. \& RoBerts, R. B. (1954). The utilization of acetate for synthesis in Escherichia coli. J. biol. Chem. 207, 81.

Mitcheld, P. \& Moyle, J. (1956). Osmotic function and structure in bacteria. Symp. Soc. gen. Microbiol. 6, 150.

Park, J. T. \& Hancock, R. (1960). A fractionation procedure for studies of the synthesis of cell wall mucopeptide and of other polymers in cells of Staphylococcus aureus. J. gen. Microbiol. 22, 249.

Plotz, P. H., Dubin, D. T. \& Davis, B. D. (1961). Influence of salts on the uptake of streptomycin by Escherichia coli. Nature, Lond. 191, 1324.

Rowley, D., Cooper, P. D., Roberts, P. W. \& Lester Smith, E. (1950). The site of action of penicillin. I. Uptake of penicillin on bacteria. Biochem. J. 46, 157.

SAGER, R. (1961). Uptake of ${ }^{14} \mathrm{C}$-streptomycin by sensitive, resistant and dependent strains of Chlamydomonas. Fed. Proc. 20, 166.

Szybalski, W. \& Mashima, S. (1959). Uptake of streptomycin by sensitive, resistant and dependent bacteria. Biochem. Biophys. Res. Comm. 1, 249.

Weibuld, C. (1955). The localisation of a permeability barrier in the cells of Bacillus megaterium. Exp. Cell Res. 9, 139. 